\title{
Aesthetic breast surgery: putting in context-a narrative review
}

\author{
Pankaj G. Roy ${ }^{1}$, Zhiyan Yan $^{1}$, Shashank Nigam ${ }^{1}$, Kavish Maheshwari ${ }^{2} \wedge$ \\ ${ }^{1}$ Department of Breast Surgery, Oxford University Hospital NHSFT, Oxford, UK; ${ }^{2}$ Department of Plastic Surgery, Bedfordshire Hospitals NHS \\ Trust, Bedfordshire, UK \\ Contributions: (I) Conception and design: PG Roy; (II) Administrative support: PG Roy; (III) Provision of study materials or patients: All authors; \\ (IV) Collection and assembly of data: None; (V) Data analysis and interpretation: None; (VI) Manuscript writing: All authors; (VII) Final approval of \\ manuscript: All authors. \\ Correspondence to: Kavish Maheshwari. Department of Plastic Surgery, Bedfordshire Hospitals NHS Trust, Bedfordshire, UK. Email: dr.kavish@gmail.com.
}

\begin{abstract}
Objective: This review article summarises the latest evidence for commonly undertaken procedures in aesthetic breast surgery with a focus on key principles of breast augmentation, reduction, and mastopexy. The paper also outlines various approaches and controversies as well as complications such as breast implant associated anaplastic large cell lymphoma (BIA-ALCL) and breast implant illness (BII) which are increasingly being recognised and becoming a challenge to manage.

Background: Changing trends of aesthetic breast surgery over the decades has warranted a continuous evolution of this field. The ability to deliver safe and appropriate care is dependent upon sound reconstructive principles and proper training. The lack of uniformity in either is a cause of concern. The impact of social media and changing perception of body image can also no longer be overlooked in the field of aesthetics and reconstruction.

Methods: Review of literature including recent journals, textbook chapters, online databases like PubMed, and current government and surgical society guidelines.

Conclusions: Breast reconstruction is based on sound surgical principles and it is imperative to follow these for the practice of this speciality. There are two important issues that revolve around this aspect of surgery. First relates to the urgent need to invest time and effort in improving regulations and outcomes in the cosmetic surgery industry. Second, it is crucial to promote and prioritize the development and training in this field as the principles of aesthetic breast surgery underpins oncoplastic breast surgery for management of cancer.
\end{abstract}

Keywords: Breast augmentation; mastopexy; breast reduction; breast implant illness (BII); reast implant associated anaplastic large cell lymphoma (BIA-ALCL)

Submitted Dec 13, 2020. Accepted for publication Jul 12, 2021.

doi: 10.21037 /gs-20-892

View this article at: https://dx.doi.org/10.21037/gs-20-892

\section{Introduction}

There is increasing use of aesthetic breast surgery over the recent decades due to population trends for greater interest in body image perfection. There are also concerns as the regulatory procedures for undertaking cosmetic surgery are not uniform across the globe, resulting in procedures being undertaken by inadequately trained personnel making vulnerable individuals seeking perfection prone to suboptimal advice and outcomes.

In this article, we discuss the impact of social media affecting the uptake of aesthetic procedures and overview of commonly sought after aesthetic procedures i.e., breast augmentation, breast reduction and mastopexy. We have focussed on BIA-ALCL and BII to review the latest evidence and address the controversies around the topics.

\footnotetext{
$\wedge$ ORCID: 0000-0003-2211-9697.
} 

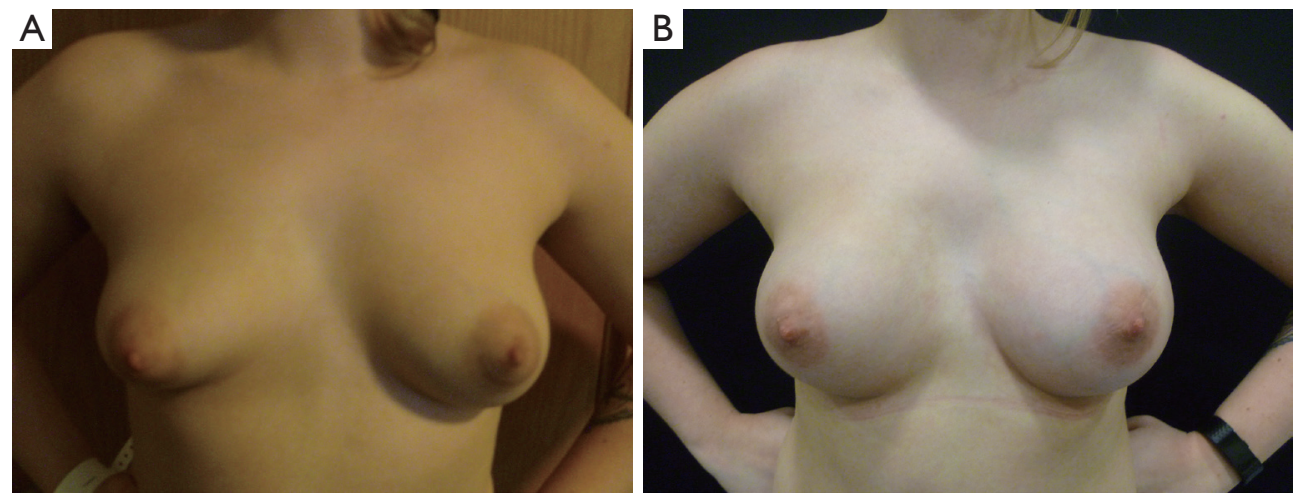

Figure 1 Breast augmentation. (A) Pre-op photo of breast augmentation; (B) post-op photo of breast augmentation: differential augmentation was undertaken to deal with pre-existing asymmetry.

We present the following article in accordance with the Narrative review reporting checklist (available at https:// dx.doi.org/10.21037/gs-20-892). The literature review has been done using various books on breast surgery, online databases like PubMed, and current government and surgical society guidelines.

\section{Impact of social media}

An optimal aesthetic outcome is a matter of perception! This perception of beauty has been described by the Tripartite Influence Model to be influenced by sociocultural influences namely peers, parents and media. These influences are mediated by two factors, namely internalization of appearance ideals and appearance comparison. If a person internalizes beauty ideals about appearances (i.e., those depicted by the media or reinforced by parents) that she/he cannot live up to or habitually engages in appearance comparison (e.g., with peers), this can result in body dissatisfaction (1). How we are perceived on SNS (social networking sites) can influence the perception of our appearance and may encourage people to want to do something about it (2).

High usage of SNS can be harmful for certain individuals in regard to their body image and psychosocial functioning (3-5). A recent study (6) exploring whether exposure to images with facial cosmetic enhancements increases desire for cosmetic surgery showed that social media use was a stronger predictor.

Patient expectations are very different when using implants for augmentation, compared to breast cancer reconstruction. For most women with breast cancer, eradication of cancer and long-term survival is the priority and aesthetics less of a concern. In the setting of augmentation, optimal aesthetic outcome is the only concern. It is important for the clinicians to understand the motivation of patients in aesthetic surgery and if their expectations are realistic. Patients motivated by social media may have unrealistic expectations.

The clinicians offering advice and consultation to the people seeking aesthetic breast surgery need to be honest and forthcoming to avoid disappointment. It is important that the psychological well-being of the patients seeking cosmetic surgery is explored at the initial meeting. These consultations are often more complex than simply discussing the surgical procedure and need appropriate training and experience.

The most commonly performed cosmetic breast procedures including breast augmentation, mastopexy and breast reduction are discussed below focusing on the key principles, considerations, approaches, risks and complications.

\section{Breast augmentation}

Breast augmentation (Figure 1) is the most commonly sought after aesthetic procedure worldwide (7), accounting for $15.6 \%$ of all total aesthetic procedures. The options include augmentation with implants or using autologous fat (lipofilling).

\section{Brief bistory of implant design}

The first breast implant used for augmentation was developed by a plastic surgeon Cronin in 1960s in Texas (8). He utilised a silicone rubber filled with silicone material in a patient volunteer. Subsequent implant designs were centred over decreasing rate of rupture and capsular contracture. 
The current silicone implant available in the market is 5 th generation form stable implant utilizing highly-cohesive gel properties. The current textured implants are claimed to be associated with lower capsular contracture.

\section{Implant crisis}

The concerns about association of breast implants with auto-immune disease (9) and that of poor durability with high rates of rupture led to the Food and Drug Administration (FDA) (10) decision to prohibit use of silicone gel implants in 1992 until 2006, when subsequent studies proved the safety of silicone implants.

In 2011, the silicone implants made by French company PIP (Poly Implant Prosthesis) were withdrawn due to the use of industrial (not medical) grade silicone resulting in high rupture rates. Another company based in Brazil manufacturing Silimed implants had their implants withdrawn in 2015 due to concerns of contaminants. In December 2018, Allergan decided against renewing CE mark leading to withdrawal of its textured implants due to higher incidence of breast implant associated anaplastic large cell lymphoma (BIA-ALCL).

\section{Pre-operative consultation}

It is important to establish patient expectations during the consult. Some patients may desire a modest augmentation while others wish a substantial and probably unrealistic augmentation. A key message to deliver is that implant based surgery is a process of care and further surgeries may be needed, in future, to address complications or maintain the aesthetic form.

Clinical examination should focus on the body habitus of the patient to ensure the augmentation is proportional. The medial fold (subcutaneous and breast tissue) thickness should be assessed to determine the plane of implant insertion with a preference for subpectoral implant, if overlying tissues are too thin to support the implant. The sternal notch to nipple distance, breast width, breast height and breast projection needs to be assessed to plan the choice of size and shape of implant.

\section{Key principles and considerations in implant augmentation}

The key considerations in implant augmentation include (11) indication, incision choice, choice of pocket plane and implant choice:
(I) Indication;

It is important to establish patient expectations to ascertain if their goals are realistic for their body habitus, chest wall shape and tissue quality. Tebbetts (12) suggests to limit the augmentation volume below $350 \mathrm{~mL}$ due to concerns of surrounding tissue pressure leading to higher risk of long-term problems. The expected breast shape after augmentation helps to choose between round and anatomical implant.

(II) Incision choice;

Infra-mammary incision is the most common incision used worldwide (13). It offers the advantage of a good access to both subglandular and subpectoral pockets with minimal violation of the breast parenchyma. The length of the scar can vary according to the size of implant. A caution needs to be practiced to ensure that scar remains hidden in infra-mammary fold after implant insertion.

Other incisions include:

(i) Peri-areolar;

This is the preferred choice if mastopexy is planned concurrently, for example, in tuberous breast (14). It is a challenging incision for small areolae and areolae with indistinct margins. There have been concerns for risk of bacterial contamination incising through the areola with resultant higher rate of capsular contracture (15) and altered nipple sensations.

(ii) Trans-axillary;

This offers the advantage of avoiding scars on the breast. This approach involves placing an expandable implant through a small incision followed by inflation. It is ideally suited for smaller non-ptotic breasts. The disadvantage is related to its remote access making it challenging to place larger implants.

(iii) Trans-umbilical;

This is the newer approach and offers the advantage of remote access avoiding a scar on the breast (13). A subcutaneous tunnel is created above the plane of the rectus fascia and is able to access both the subglandular and subpectoral pockets for the placement of tissue expanders. Trans-umbilical and transaxillary approaches do not allow secondary procedures to be performed, if needed in the 
future.

(III) Choice of pocket plane;

The choice of pocket plane include subglandular, subfascial or subpectoral. An implant placed in the subglandular plane has less morbidity compared to submuscular approach that involves dissection of the pectoralis muscle. However it carries a risk of implant visibility and palpability especially in thin patients.

Subglandular placement of implant is suitable for patients with good medial fold thickness (volume of overlying breast tissue and subcutaneous layer greater than $2 \mathrm{~cm}$ ). It avoids muscle animation associated with subpectoral placement. Whilst the subglandular placement is said to be associated with a higher risk of capsular contracture (16) and potential interference with mammographic interpretation (14), one study (17) found no difference in capsular contracture between the two approaches.

Tebbetts (18) described dual plane approach whereby implant lies partially behind pectoral muscle and partially behind the breast. This approach provides good muscular cover of the upper pole of implant with adequate lower pole expansion making it preferable over total submuscular approach.

(IV) Implant choice;

An ideal implant is the one that produces long lasting aesthetically pleasing result with low risk of capsular contracture rate hence low reoperation rates.

The implant choice can be broadly considered in terms of (19):

(i) Saline or silicone gel implant fill;

The FDA restricted the use of silicone implant for breast augmentation in USA from 1992 to 2006; thus saline implants were the only type used prior to 2006. The benefits include smaller incision for surgery and easier detection of implant deflation. There is no convincing data demonstrating that either saline or silicone implants are associated with less capsular contracture (20).

(ii) Round or anatomical implant shape;

Both anatomical and round implants seem equivalent in producing good aesthetic results depending on patient preference $(21,22)$.

(iii) Smooth or textured surface implant shell;

Texturising of implant shell reduces capsular contracture $(23,24)$. However, there are concerns that textured implants are associated with BIA-ALCL (see below).

(V) Fixed volume or adjustable implants;

The preference is usually for fixed volume implants for aesthetic procedures however adjustable implant e.g., Mentor Becker implant with an attached port is an option in difficult cases such as tuberous breasts and in breast reconstruction (19).

\section{Operative procedure}

The breast footprint should be marked in an upright position pre-operatively.

Implant augmentation is performed under general anaesthesia with single dose of antibiotics given at induction to prevent infection (25). The key points are:

(I) Do not over dissect the pocket medially, as that could result in symmastia or implant palpability.

(II) Ensure meticulous haemostasis.

Following measures are advised during surgery to reduce risk of infection (26):

(I) Change of gloves prior to implant handling and minimising implant exposure prior to insertion.

(II) Washing instruments and implant pocket with antiseptic/antibiotic solution.

(III) Avoiding implant contact with skin by use of insertion device such as Keller funnel.

(IV) Minimising theatre personnel traffic in operation theatre and adopting laminar flow in theatres.

(V) Prophylactic antibiotics at induction.

(VI) A nipple shield is often used to reduce bacterial contamination.

Routine use of post-operative drains is not recommended. Some surgeons advocate use of specific post operative support bra to help maintain implant position.

\section{Complications (27)}

(I) Bleeding/haematoma (1\% risk): re-operation and washout is recommended.

(II) Infection (ideally $<1 \%$ ).

(III) Capsular contracture: the rate of adverse capsular contracture requiring operation is $10 \%$ at 10 years (28).

(IV) Implant palpability/visibility/wrinkling: this is more often seen with smooth implants and implants in subglandular position.

(V) Implant rotation: seen with anatomical implants. 
(VI) Implant loss (aimed at $<5 \%$ ): if the implant gets infected, antibiotics are rarely effective and removal of the implant is usually required.

(VII) Leakage of silicone. If implant ruptures, the silicone gel will usually remain within the capsule that the body forms (intracapsular rupture), and can be removed if the ruptured implant is removed. Occasionally the silicone can spread outside the capsule and into the breast, surrounding tissues (extracapsular rupture) or into the axillary nodes, forming silicone granulomas.

\section{BIA-ALCL}

BIA-ALCL is a rare type of T-cell non-Hodgkin lymphoma related to breast implants and as of April 2020, there have been 800 confirmed cases worldwide with 33 deaths attributed to ALCL (29). Although the etiology of BIAALCL is not completely elucidated, the possible theories include chronic inflammatory response, immune response, type of the implant (smooth or textured), hereditary predisposition or bacteria biofilm (30,31).

The most common presentation is a large spontaneous seroma around implant, of varying duration (usually more than a year), following cosmetic or reconstructive surgery with textured implants. The lymphoma develops from the luminal aspect in $85 \%$ cases usually causing breast distortion, swelling, or asymmetry. Rarely, bilateral breast involvement has been reported. Around $15 \%$ patients may present with a palpable mass, or a combination of mass and effusion (29). So far there have been no cases of BIA-ALCL with smooth implants only (32). Other less common presentations can be skin ulcerations, erythema, lymphadenopathy, and B symptoms (29).

As per the recent UK guidelines, these patients should be worked up by triple assessment which includes clinical examination with breast ultrasound and/or MRI and aspiration of the fluid and/or biopsy of the mass. The histopathological assessment is done in two stages. The first is morphological evaluation of the tumour cells in the fluid aspirate or mass biopsy. This is then followed by secondary assessment by immunohistochemistry, specially CD30. The sensitivity of cytological assessment is around $78 \%$. Additional biomarkers (ALK negativity) and flow cytometry may be required for confirming the diagnosis. PET-CT is recommended to stage the disease once diagnosed. In case of clinical or radiological suspicion, referral to a tertiary centre is recommended. In the absence of suspicion, patients should be followed up at 3 months to ensure that the swelling does not recur (29).

The majority of implant associated ALCL are diagnosed early and treated with curative surgery that involves removal of implant with en bloc total capsulectomy. The advanced cases (Stage II-IV) require systemic chemotherapy as per NCCN guidelines (33). Local radiotherapy is suggested for incomplete local excision or chest wall invasion. However, there is no recommendation for screening or prophylactic removal of breast implants for asymptomatic patients irrespective of family history or genetic predisposition for breast cancer (34).

The recommendation is to have joint patient follow-up between the surgical and haemato-oncology teams every 3 to 6 months, for a minimum of 2 years. While clinical assessment is required, there is a lack of evidence to support routine imaging surveillance (29).

MHRA (Medicines and Healthcare products Regulatory Agency) in UK has mandated that all new cases are reported via 'yellow card scheme' (35). Various national and international authorities mandate surgeons to specifically include BIA-ALCL in the process of informed consent and preoperative counselling with variable compliance (36). In $\mathrm{UK}$, this advice is being enforced via professional societies such as ABS, BAPRAS and government via MHRA.

\section{Breast implant associated illness (BII)}

BII is a term used for women who have breast implants and describe a variety of symptoms including fatigue, chest pain, hair loss, chronic pain, body odour, anxiety, brain fog, sleep disturbances or depression. First described in the 1980s where there was concern that breast implants may be associated with auto-immune diseases such as rheumatoid arthritis or Sjögren disease. Subsequent epidemiological studies proved that there was no association between implants and autoimmune diseases (37-40). However there are some epidemiological studies to suggest higher incidence of autoimmune disorder in women with silicone implants (41). The potential of breast implants being adjuvants, that enhance an antigen-specific immune response, without triggering one of their own is being extensively investigated under a larger entity known as 'Autoimmune/inflammatory syndrome induced by adjuvants (ASIA)' (42), though at present conclusive evidence is lacking (43).

\section{Controversy}

This entity is controversial due to lack of adequate scientific 
data and an established pathogenesis for these symptoms (44), which is turn leads to a degree of mistrust and disbelief (45). There are support groups for women suffering from such symptoms on the internet, where evidence based medicine get replaced by belief based medicine $(45,46)$. The challenge faced by these patients is the reluctance on the part of health care givers to acknowledge their symptoms and lack of compassion (45). In the era of evidence-based medicine, there is a need for causal relationship to be established.

\section{Pathogenesis}

There are two predominant theories to explain these symptoms; psychological (47) and immunological (44).

Dush suggested a psychological model as complaints overlapped with fibromyalgia, irritable bowel syndrome, chronic fatigue syndrome etc. (47). The concept of somatization can be applied to this entity, when the symptoms are considered to be functional rather than organic, as these women suffer from symptoms and disability, disproportionate to or in the absence of demonstrable tissue abnormalities. One study (48) found women undergoing implants had higher anxiety levels when compared to female undergraduate students. There is suggestion that women with breast implants had a higher self reported rate of psychotropic medication use (49).

The pre-existing symptoms undergo change as a result of an emotional upheaval, psychological disturbance, a medical illness, stress or any other factor, followed by a change in attribution to implants. Further internal and social mediation consolidates the idea that implants are the cause, after which there is tendency for disregard to alternate explanations. Participation in online support groups makes it challenging for the patient to come out of this cycle of somatization (47).

Immunological theory (44): Silicone has long been considered an immunological adjuvant substance that enhances an antigen-specific immune response without triggering one on its own (50,51). Shoenfeld et al. suggested the term ASIA (autoimmune/inflammatory syndrome induced by adjuvants) for a group of non-specific conditions thought to arise from environmental adjuvant agents that trigger the immune system in genetically susceptible subjects (52). Watad et al. (42) analyzed 300 patients on their ASIA registry, amongst which 105 patients had foreign material identified prior to development of ASIA, which included cosmetic fillers $(38.8 \%)$, metal $(43.7 \%)$, and silicone filled breast implants (17.5\%). Though no causal relation could be established, such registries could help gather data. A large cross sectional study spread over 20 years of data on 2 million members found that women with silicone breast implants had a higher likelihood of an autoimmune/rheumatic disorder (41). In another study, 32 patients with breast implants were identified to have ASIA and the median onset of symptoms was 10 years [2-24] years after implant placement (53).

Several reasons have been postulated for an immunological reaction including biofilm, deposition of host proteins, silicone migration and genetic susceptibility (50).

\section{Patient management}

There is need for compassionate consultation for these patients as most women in this situation are stressed and seeking solution. A detailed discussion of symptoms, clinical examination and imaging as appropriate to rule out implant related complications should be carried out routinely. An expert opinion from a rheumatologist or another specialist (depending on the symptoms) is worth considering ruling out an organic cause for symptoms.

Blood tests along with autoimmune disease markers could be considered for these patients to help determining a possible systemic illness explaining symptoms (44). There is suggestion that these could also help in determining prognosis, if explantation is being offered to patients as shown in Table 1 (44).

There is a suggestion for classification on the basis of their pre-existing disease and likely outcome $(44,54)$ (Table 1).

Managing these patients requires good clinical skills and excellent communication (55), as most patients on the support group had grievances with their operating surgeons for lack of compassion (45).

It is important to carefully select patient for explantation after careful counseling $(44,47,55)$. The surgeon must discuss available scientific evidence and the complications of explantation with a possibility that their symptoms may or may not improve. Explantation alone is a solution for most patients though there are some that advocate en bloc removal of the implant with the capsule. There is no evidence that en bloc removal can resolve these symptoms. En bloc capsulectomy carries a higher risk of complications including hemorrhage, pneumothorax and suboptimal aesthetic outcome; making it difficult to justify en bloc capsulectomy in the absence of evidence (55).

The British Association of Aesthetic Plastic Surgeons (56) states that on average $50 \%$ of women who self-identify BII feel temporary or permanent relief after implant removal; but 
Table 1 Classification of types of BII

\begin{tabular}{lll}
\hline Bll type & Underlying disease & Prognosis following explantation \\
\hline A & No proven disease & Most likely improvement \\
B & Abnormal markers, but no definite diagnosis & Short term symptom improvement \\
C & Proven autoimmune disease & Unlikely to have symptom improvement \\
\hline
\end{tabular}

the outcome after implants removal cannot be ascertained prior to surgery. It is important for clinicians to manage patients individually paying attention to their concerns.

\section{Future course}

Patients following explanation need to be followed up longer to study the impact of implant removal in the longterm (44). There is still lack of consensus whether this entity should form a part of routine consent for women undergoing breast implant surgery as the true existence of this entity is still in question $(43,57)$.

The Medicines and health Regulatory Agency MHRA (58) provides up to date guidance and is a helpful tool to advice patients.

\section{Fat transfer for breast augmentation}

Lipofilling is increasingly used to contour and is considered safe; however, significant volume loss and the number of procedures required limit its utility for breast augmentation. Not all women are suitable, as there needs to be a good donor site for the procedure.

Lipoaugmentation is suitable for patients who desire a moderate increase of breast volume, or who desire recovery of the fullness they had before weight loss or pregnancy. The ideal patient is a young woman with a slim upper body, moderately small breasts, and sufficient regional adiposity of the lower body to allow one or even two lipomodelling sessions.

The key advantage of the option is the autologous nature of the augmentation thus reducing the need for further surgeries in future that may be indicated for implant related complications. It is recommended that fat injection is carried out either in subdermal plane or in retromammary space avoiding intraglandular injection (59).

\section{Potential concerns}

(I) Interference with breast assessment due to fat necrosis/ calcifications although mammogram and/or ultrasound is usually diagnostic. There may be a need for biopsy to confirm the diagnosis beyond doubt in some situations.

(II) Safety of lipofilling has been questioned with regards to risk of breast cancer; however there is no evidence to support that in clinical studies (60-62).

Complications $(61,63)$ : fat transfer is a low morbidity procedure in experienced hands. The potential risks are listed below:

Donor site:

(I) Extensive bruising and swelling;

(II) Pain and discomfort;

(III) Paraesthesia or numbness (this could be long-term);

(IV) Infection;

(V) Lumpiness or contour irregularities;

(VI) Very rarely, skin necrosis;

(VII) Injury to deeper structures is very rare (e.g., pneumothorax, bowel injury).

Recipient site:

(I) Inadequate fat take (>30\% fat absorption);

(II) Fat necrosis;

(III) Oil cysts;

(IV) Infection;

(V) Swelling/bruising.

Lipoaugmentation is a potential option for unilateral hypoplastic tuberous breast with good outcomes reported $(61,64)$, breast asymmetry and Poland's syndrome. However, breast implants still remain the choice for breast augmentation in majority.

\section{Mastopexy}

Mastopexy (Figure 2) encompasses aesthetic correction of a breast by altering its shape and/or size. The main aim of the procedure is to correct the discrepancy between skin and parenchyma in order to give the appearance of a more youthful breast. It may or may not be supplemented with augmentation.

With the trend of breast cancer surgery shifting towards breast conservation (65) and the need to address 

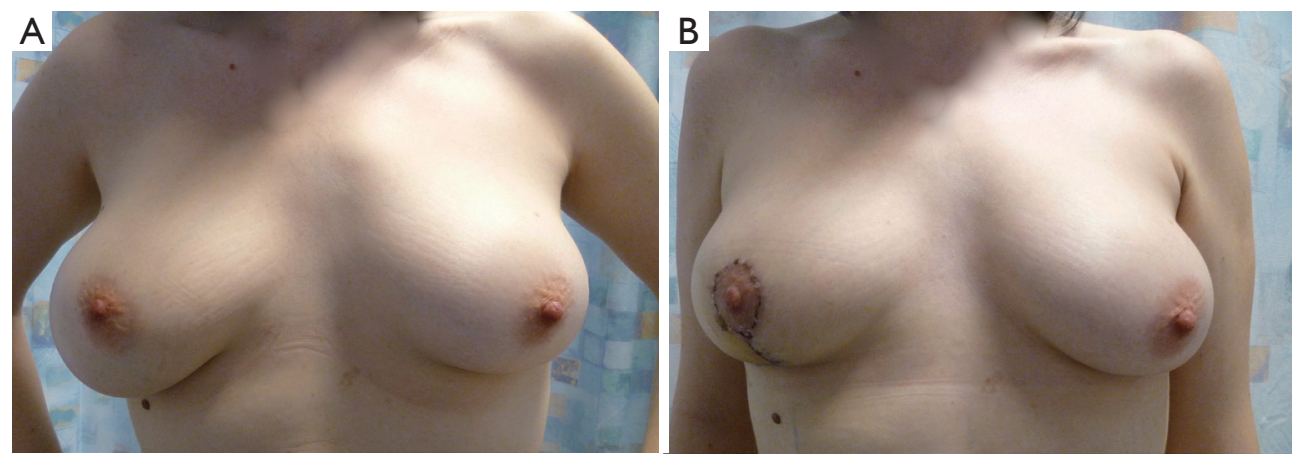

Figure 2 Breast mastopexy. (A) Pre-op photo of breast asymmetry; (B) post-op photo of unilateral mastopexy to correct developmental asymmetry.

Table 2 Regnault's grading of ptosis (71)

\begin{tabular}{lcl}
\hline Grade & Degree & Description \\
\hline Pseudoptosis & - & Nipple at the IMF but gland below the IMF \\
I & Mild & Nipple at or within $1 \mathrm{~cm}$ below the IMF \\
II & Moderate & Nipple below the IMF but above the lowest point of the breast \\
III & Severe & Nipple at the lowest point of the breast \\
\hline
\end{tabular}

correction of shape discrepancy, the adoption of principles of mastopexy is increasing along with improvement in the outcomes (66). With greater emphasis on psychosocial outcomes of breast cancer treatment, patient's appearance and satisfaction are being acknowledged, with a focus on improving their quality of life $(67,68)$.

The indications of mastopexy include:

(I) Aesthetic mastopexy for ptotic breasts;

(II) Correction of asymmetry;

(III) For women with breast cancer: to facilitate breast conservation on the cancer side (65) and mastopexy on the contralateral side for symmetry (69).

\section{Patient selection}

The pre-operative assessment includes assessment of patient's anatomy and their expectations (66). The assessment can broadly be divided into following aspects:

* Oncological evaluation (67):

- Tumour size and location $v s$. breast shape and size;

- Need for adjuvant therapies.

- Breast anatomy (66):

It is important to analyze breast in three dimensions. Two dimensions form the breast footprint and the third dimension is the shape (70);

- $\mathrm{BMI} ;$

- Breast measurements—base width, sternal notch to nipple distance, nipple to inframammary fold (IMF) distance, areola diameter, inter-nipple distance;

- Assessment of asymmetry—size, shape, nipple position, areolar geometry;

- Location of breast and its footprint (70);

- Chest wall and spine abnormalities;

- Assessment of ptosis (Table 2);

- Soft tissue dynamics.

- Patient factors (72):

- Patient's reconstructive goals and expectations;

- Age and co-morbidities such as diabetes, immunosuppression, connective tissue disorders;

- Smoking status;

- Medical history.

* Imaging:

- Oncological imaging;

- Photographic documentation is advisable.

* Discussion of risks and expected outcomes: 
Thorough discussion of options including risks associated with surgery along with discussion of ensuing scars and their appearance (66). They need to be educated regarding how breast tissues behave and drop with age (72).

It is important for patient with breast cancer treated with breast conservation surgery and radiotherapy to understand that the two breasts will behave differently with time due to the impact of radiotherapy on the cancer side.

\section{Principles of mastopexy}

Mastopexy can be broadly discussed on the basis of skin incisions and the resulting scars as well as the various pedicles that can be used to preserve the nipple-areola complex.

The skin incisions are broadly classified as $(66,72,73)$ :

* Circumareolar/round block mastopexy (74);

* Vertical scar mastopexy $(75,76)$;

* Inverted T-scar/Wise pattern mastopexy (77).

The circumareolar technique could be employed for breasts with minimal ptosis with minimal scarring. This technique has a steep learning curve and results in flattening of the breast as well as widening of the scar with time (66).

Vertical scars could be used for all grades of ptosis (described below) and commonly used with superior or medial pedicle for the nipple-areola complex. It carries the advantage of less scarring and good breast projection. For very wide and ptotic breasts, a wise pattern incision (with anchor shaped scar) is preferred to achieve simultaneous reduction in breast volume. This could be undertaken with any of the pedicles for nipple vascularity.

The nipple areola complex (NAC) is preserved with the help of de-epithelialized pedicles, which bring its blood supply and may maintain sensation. The choice is determined by tumour location, breast volume, degree of ptosis and soft tissue dynamics (73). The commonly used pedicles are:

- Superior pedicle (78);

* Supero-medial pedicle (79);

* Medial pedicle $(73,75)$;

* Inferior pedicle (80).

The orientation of a pedicle is to maximize the vascularity of the nipple-areola complex. It needs to be wide enough to maximize vascularity, but also narrow enough to allow reduction of the breast and avoid venous congestion.

The superior pedicle is generally used for smaller resections and avoided in those with a sternal notch to nipple distance of $>40 \mathrm{~cm}$. This maintains a good upper pole fullness and breast projection, but carry a higher risk of loss of nipple sensation (81).

A medial or a supero-medial pedicle carries the same advantage of upper pole fullness and projection with an added advantage of maintained nipple sensations.

The inferior pedicle is the most commonly used and is safe for larger resections.

\section{Complications}

The potential complications include $(82,83)$ :

(I) Immediate complications: hematoma, infection, seroma, venous thromboembolism;

(II) Long term complications:

(i) Scar related: hypertrophy, unaesthetic appearance;

(ii) Wound related: dehiscence, delayed healing;

(iii) Unsatisfactory breast volume or shape;

(iv) Nipple-related complication: retraction, asymmetry, necrosis, loss of sensations;

(v) Others: fat necrosis, skin flap necrosis, inability to breastfeed.

\section{Reduction mammoplasty}

Macromastia is a benign condition caused by breast proliferation resulting from abnormal response of the breasts to circulating estrogens. These breasts comprise mostly of fibrous tissue and fat, with some glandular tissue. These women usually have normal blood levels of estrogen and normal number of estrogen receptors on the breast tissue.

Juvenile or virginal hypertrophy of the breast is rapid breast enlargement starting during the puberty, usually between 11 to 14 years of age. Gigantomastia is a condition of mammary hypertrophy defined by the amount of breast tissue needed to be excised, usually being between 1,000 to $2,000 \mathrm{gm}$.

Women with mammary hypertrophy usually present with physical symptoms such as neck pain, upper back pain, shoulder pain, bra strap grooving, rashes, intertriginous skin maceration, infections, postural problems, loss of nipple sensations, issues with finding good fitting clothes and limited ability to exercise. Psychological symptoms are common. Conservative management options such as weight reduction and use of special bras have not been found to be very effective. Surgical intervention 'reduction 

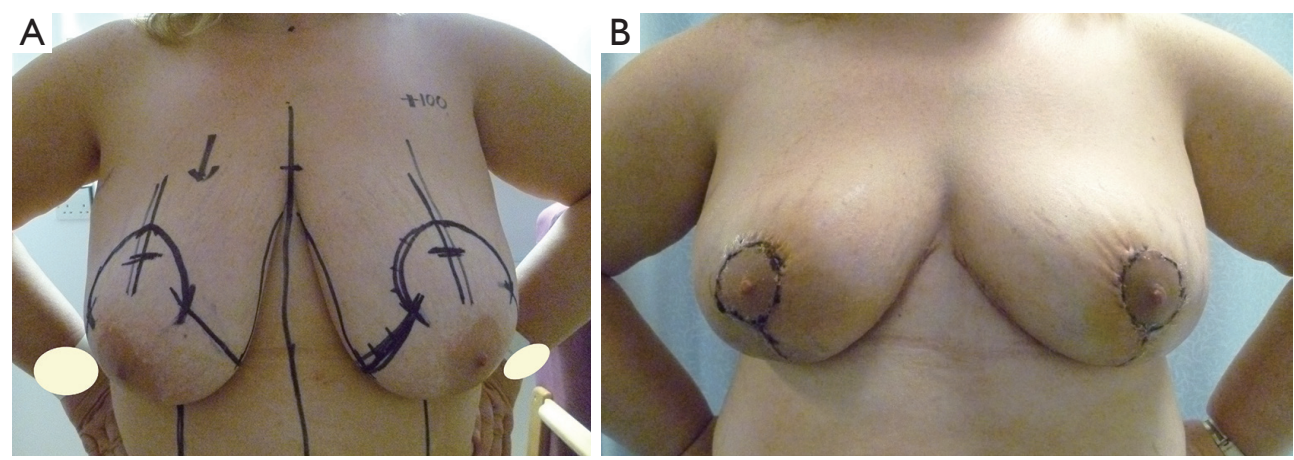

Figure 3 Breast reduction. (A) Pre-op photo of enlarged breasts; (B) post-op photos of wise pattern bilateral breast reduction.

mammoplasty' relieves most symptoms with significant improvement in patient satisfaction (84).

The different skin and parenchymal resection patterns and the pedicles are similar to those listed above (mastopexy section).

Wise pattern reduction (anchor shaped scar) (Figure 3) is criticized for its extent of scarring and bottoming out of breasts resulting in 'boxy shape' when combined with inferior pedicle (inferior pedicle is the most commonly used pedicle with this approach). Scars in the transverse plane along the inframammary fold can be kept short, by not going beyond the anterior axillary fold laterally. The lateral excess folds could instead be managed with liposuction. Flattening or hollowing of the breast medially can be prevented by leaving breast tissue medially over the pectoral muscle.

The principle behind vertical scar approach is that it is the lower pole tissue that leads to ptosis, and its resection with bringing together of the medial and lateral parenchymal pillars is expected to result in coning of the breast. This results in an aesthetic and projected breast which is likely to remain consistent with time.

Thorek's technique (85) of amputation of inferior pole of breast and free nipple graft described in 1922 is still in vogue for very large and pendulous breasts.

All patients should be marked pre-operatively in the upright position on the day of surgery (this is key to success) and any temptation to change the markings whilst operating in supine position should be resisted. It is important to document and correct pre-existing breast asymmetry.

The commonly used pedicles are briefly discussed below:

(I) Inferior pedicle breast reduction:

This technique employs excision of breast tissue as a crescent from the superior, lateral $(+/-$ medial aspect) of the breast whilst maintaining the blood supply of nipple-areola complex on the inferior pedicle, based on the 4th and 5th intercostal artery perforators. It is important to realise that the blood vessels enter the parenchyma on the posterior aspect so care needs to be taken when mobilising the pedicle to avoid devascularisation. The areola is usually marked intra-operatively towards the end of surgery, by making the patient upright, particularly in patients with very large or pendulous breast.

(II) Superior, supero-medial or medial pedicle breast reduction:

These pedicles are based on $2 \mathrm{nd}$ and $3 \mathrm{rd}$ intercostal artery perforators. The choice of superior versus supero-medial or medial pedicle depends on the degree of transposition of nipple. Superior pedicle is restricted in allowing nipple movement between $2-5 \mathrm{~cm}$ otherwise the wound closure would result in venous congestion with potential threat to the integrity of nipple areola complex. If the nipple is expected to move up more than $5 \mathrm{~cm}$, supero-medial or medial pedicle is desirable.

(III) Round block/Benelli's technique (86):

The skin reduction is performed around the areola thereby minimizing the scar. This procedure is limited in amount of reduction (up to $200 \mathrm{gm}$ ) and is criticised for the flattening of the breast.

The choice of pedicle depends on multiple factors, which includes surgeon's familiarity and patient related factors like the shape and size of breast desired and the length of pedicle designed. As the sternal notch to nipple distance increases $(>40 \mathrm{~cm})$, the risk of vascular compromise of superior or supero-medial pedicle increases. 
Similarly with increasing inframammary fold to nipple distance $(>22 \mathrm{~cm})$, perfusion of the inferior pedicle might be at risk.

(IV) Extreme macromastia:

In cases of extreme macromastia, with sternal notch to nipple distance $>40 \mathrm{~cm}$, preserving the perfusion of nipple on a pedicle might be challenging. In such a case either a free nipple graft or a breast reduction with sacrifice of nipple areola complex with the option of immediate/delayed nipple reconstruction could be considered.

\section{Melon-slice breast reduction or wedge mammoplasty}

This is an option for women wishing to avoid a long procedure for medical reasons or otherwise, as this offers a quick and easy way with expedited post-op recovery and reduced risks and complications; albeit with loss of nipple-areolar complex.

\section{Risks and complications of breast reduction}

The risk of wound problems and infection is higher in active smokers, diabetics and women with higher BMI. Up to $5 \%$ of patients can have breakdown of the wound at the T-junction. This leads to a delay in wound healing but usually heals by secondary intention with the help of dressings. Partial or total loss of nipple sensations is common, although sensation returns in many patients. It's important to counsel young women for risk of inability to breast feed after breast reduction. Women undergoing this surgery should be informed that the shape of reduced breasts may change with time, particularly with changes in body weight, ageing and pregnancy.

\section{Putting aesthetic surgery in context of breast cancer}

Whilst the expectations and demands of a person wishing aesthetic breast surgery are very different for those undergoing surgery for breast cancer, the principles and core skills involved in surgery are transferable. This article highlights the principles for oncoplastic breast surgeons to help integrate breast aesthetics whilst planning oncological surgery. It is also important for surgeons to ascertain outcomes that are realistic, achievable and hopefully sustainable for a patient and in the context of cancer surgery, to understand the impact of other treatments such as radiotherapy on the surgical outcomes and vice versa.
The application of mastopexy and breast reduction for breast conservation surgery to treat breast cancer requires skills that go beyond the standard techniques described above and often when there is very little time and opportunity to modify patient risk factors. The contralateral breast symmetrisation is commonly undertaken at a later stage once the treatment of breast cancer is completed. The planning of these procedures is often complex or at least not straightforward to match the breast that has been through surgery and radiotherapy.

With the advances in implant reconstruction techniques and availability of biological and synthetic meshes, direct to implant reconstruction is gaining popularity both with clinicians and patients due to the obvious benefits. This requires good knowledge of implants and clinical experience with the techniques and ability to manage complications. Women with small breasts and requiring mastectomy might wish for augmented reconstruction ('as a silver lining to the cloud') and contralateral augmentation to achieve a breast size that is more proportionate to their body habitus and this is not unreasonable given the circumstances. However, this requires a significant experience to be able to optimally select totally different implants for two sides and achieve a reasonable symmetry.

The current training programmes are not uniform across the globe resulting in variation in practices with regards to adoption of oncoplastic breast surgery techniques. This article highlights the importance of aesthetic surgery training for breast surgeons to improve the outcomes after breast cancer surgery.

\section{Conclusions}

There is need for integrated training programmes (breast surgery and plastic surgery) globally to improve the outcomes for breast cancer, which is affecting a disproportionate number of women across the globe. Similarly, there is need for better regulation of aesthetic breast surgery, particularly in the current era with social media hype, to protect vulnerable individuals.

\section{Acknowledgments}

Funding: None.

\section{Footnote}

Reporting Checklist: The authors have completed the 
Narrative Review reporting checklist. Available at https:// dx.doi.org/10.21037/gs-20-892

Peer Review File: Available at https://dx.doi.org/10.21037/ gs-20-892

Conflicts of Interest: All authors have completed the ICMJE uniform disclosure form (available at https://dx.doi. org/10.21037/gs-20-892). The authors have no conflicts of interest to declare.

Ethical Statement: The authors are accountable for all aspects of the work in ensuring that questions related to the accuracy or integrity of any part of the work are appropriately investigated and resolved.

Open Access Statement: This is an Open Access article distributed in accordance with the Creative Commons Attribution-NonCommercial-NoDerivs 4.0 International License (CC BY-NC-ND 4.0), which permits the noncommercial replication and distribution of the article with the strict proviso that no changes or edits are made and the original work is properly cited (including links to both the formal publication through the relevant DOI and the license). See: https://creativecommons.org/licenses/by-nc-nd/4.0/.

\section{References}

1. Thompson JK, Heinberg LJ, Altabe M, et al. Exacting Beauty: Theory, Assessment, and Treatment of Body Image Disturbance. American Psychological Association, 2004. doi: http://dx.doi.org/10.1037/10312-000.

2. de Vries DA, Peter J, Nikken P, et al. The Effect of Social Network Site Use on Appearance Investment and Desire for Cosmetic Surgery Among Adolescent Boys and Girls. Sex Roles 2014;71:283-95.

3. Brown Z, Tiggemann M. Attractive celebrity and peer images on Instagram: Effect on women's mood and body image. Body Image 2016;19:37-43.

4. Holland G, Tiggemann M. A systematic review of the impact of the use of social networking sites on body image and disordered eating outcomes. Body Image 2016;17:100-10.

5. \#StatusOfMind Social media and young people's mental health and wellbeing by Royal Society For Public Health. Available online: https://www.rsph.org.uk/uploads/assets/ uploaded/d125b27c-0b62-41c5-a2c0155a8887cd01.pdf. Accessed February 16, 2020.
6. Walker CE, Krumhuber EG, Dayan S, et al. Effects of social media use on desire for cosmetic surgery among young women. Curr Psychol 2021;40:3355-64.

7. INTERNATIONAL SURVEY ON AESTHETIC/ COSMETIC PROCEDURES PERFORMED IN 2017.

Available online: https://www.isaps.org/wp-content/ uploads/2018/10/ISAPS_2017_International_Study_ Cosmetic_Procedures.pdf. Accessed February 16, 2020.

8. Cronin TD, Brauer RO. Augmentation mammaplasty. Surg Clin North Am 1971;51:441-52.

9. Sergott TJ, Limoli JP, Baldwin CM Jr, et al. Human adjuvant disease, possible autoimmune disease after silicone implantation: a review of the literature, case studies, and speculation for the future. Plast Reconstr Surg 1986;78:104-14.

10. Kessler DA. The basis of the FDA's decision on breast implants. N Engl J Med 1992;326:1713-5.

11. Adams WP Jr, Mallucci P. Breast augmentation. Plast Reconstr Surg 2012;130:597e-611e.

12. Tebbetts JB. A surgical perspective from two decades of breast augmentation: toward state of the art in 2001. Clin Plast Surg 2001;28:425-34, v.

13. Pound EC 3rd, Pound EC Jr. Transumbilical breast augmentation (TUBA): patient selection, technique, and clinical experience. Clin Plast Surg 2001;28:597-605.

14. Silverstein MJ, Handel N, Gamagami P. The effect of silicone-gel-filled implants on mammography. Cancer 1991;68:1159-63.

15. Persichetti P, Cagli B, Tenna S, et al. Decision making in the treatment of tuberous and tubular breasts: volume adjustment as a crucial stage in the surgical strategy. Aesthetic Plast Surg 2005;29:482-8.

16. Biggs TM. Augmentation mammaplasty: a comparative analysis. Plast Reconstr Surg 1999;103:1761-2; discussion 1763-5.

17. Strasser EJ. Results of subglandular versus subpectoral augmentation over time: one surgeon's observations. Aesthet Surg J 2006;26:45-50.

18. Tebbetts JB. Dual plane breast augmentation: optimizing implant-soft-tissue relationships in a wide range of breast types. Plast Reconstr Surg 2006;118:81S-98S; discussion 99S-102S.

19. Breast Implants I FDA. Available online: https://www. fda.gov/medical-devices/implants-and-prosthetics/breastimplants. Accessed February 16, 2020.

20. Schaub TA, Ahmad J, Rohrich RJ. Capsular contracture with breast implants in the cosmetic patient: saline versus silicone--a systematic review of the literature. Plast 
Reconstr Surg 2010;126:2140-9.

21. Bronz G. A comparison of naturally shaped and round implants. Aesthet Surg J 2002;22:238-46.

22. Friedman T, Davidovitch N, Scheflan M. Comparative double blind clinical study on round versus shaped cohesive gel implants. Aesthet Surg J 2006;26:530-6.

23. Wong CH, Samuel M, Tan BK, et al. Capsular contracture in subglandular breast augmentation with textured versus smooth breast implants: a systematic review. Plast Reconstr Surg 2006;118:1224-36.

24. Barnsley GP, Sigurdson LJ, Barnsley SE. Textured surface breast implants in the prevention of capsular contracture among breast augmentation patients: a meta-analysis of randomized controlled trials. Plast Reconstr Surg 2006;117:2182-90.

25. Khan UD. Breast augmentation, antibiotic prophylaxis, and infection: comparative analysis of 1,628 primary augmentation mammoplasties assessing the role and efficacy of antibiotics prophylaxis duration. Aesthetic Plast Surg 2010;34:42-7.

26. Adams WP Jr, Culbertson EJ, Deva AK, et al. Macrotextured Breast Implants with Defined Steps to Minimize Bacterial Contamination around the Device: Experience in 42,000 Implants. Plast Reconstr Surg 2017;140:427-31.

27. What complications can occur I BAPRAS. Available online: http://www.bapras.org.uk/public/patientinformation/surgery-guides/breast-enlargement/whatcomplications-can-occur. Accessed February 16, 2020.

28. BAPRAS. Your Guide to Breast Augmentation 2014. Available online: https://www.bapras.org.uk/docs/defaultsource/Patient-Information-Booklets/rcs_bapras_guide_ breast_augmentation.pdf?sfvrsn=4. Accessed February 16, 2020.

29. Turton P, El-Sharkawi D, Lyburn I, et al. UK Guidelines on the Diagnosis and Treatment of Breast ImplantAssociated Anaplastic Large Cell Lymphoma (BIA-ALCL) on behalf of the Medicines and Healthcare products Regulatory Agency (MHRA) Plastic, Reconstructive and Aesthetic Surgery Expert Advisory Group (PRASEAG). J Plast Reconstr Aesthet Surg 2021;74:13-29.

30. Ferreri AJ, Govi S, Pileri SA, et al. Anaplastic large cell lymphoma, ALK-negative. Crit Rev Oncol Hematol 2013;85:206-15.

31. Hu H, Jacombs A, Vickery K, et al. Chronic biofilm infection in breast implants is associated with an increased T-cell lymphocytic infiltrate: implications for breast implant-associated lymphoma. Plast Reconstr Surg
2015;135:319-29.

32. Doren EL, Miranda RN, Selber JC, et al. U.S. Epidemiology of Breast Implant-Associated Anaplastic Large Cell Lymphoma. Plast Reconstr Surg 2017;139:1042-50.

33. Clemens MW, Jacobsen ED, Horwitz SM. 2019 NCCN Consensus Guidelines on the Diagnosis and Treatment of Breast Implant-Associated Anaplastic Large Cell Lymphoma (BIA-ALCL). Aesthet Surg J 2019;39:S3-S13.

34. Clemens MW, Horwitz SM. NCCN Consensus Guidelines for the Diagnosis and Management of Breast Implant-Associated Anaplastic Large Cell Lymphoma. Aesthet Surg J 2017;37:285-9.

35. Breast implants and Anaplastic Large Cell Lymphoma (ALCL) - GOV.UK. Available online: https://www.gov. uk/guidance/breast-implants-and-anaplastic-large-celllymphoma-alcl. Accessed July 8, 2020.

36. Pittman TA, Fan KL, Rudolph MA. Anaplastic Large Cell Lymphoma: Emerging Consent and Management Patterns among American and International Board Certified Plastic Surgeons. Plast Reconstr Surg 2016;138:811e-8e.

37. Hochberg MC, Perlmutter DL, Medsger TA Jr, et al. Lack of association between augmentation mammoplasty and systemic sclerosis (scleroderma). Arthritis Rheum 1996;39:1125-31.

38. Sánchez-Guerrero J, Colditz GA, Karlson EW, et al. Silicone breast implants and the risk of connective-tissue diseases and symptoms. N Engl J Med 1995;332:1666-70.

39. Institute of Medicine (US) Committee on the Safety of Silicone Breast Implants; Bondurant S, Ernster V, Herdman R. Safety of Silicone Breast Implants. Washington (DC): National Academies Press (US), 1999.

40. Lee IM, Cook NR, Shadick NA, et al. Prospective cohort study of breast implants and the risk of connective-tissue diseases. Int J Epidemiol 2011;40:230-8.

41. Watad A, Rosenberg V, Tiosano S, et al. Silicone breast implants and the risk of autoimmune/rheumatic disorders: a real-world analysis. Int J Epidemiol 2018;47:1846-54.

42. Watad A, Quaresma M, Bragazzi NL, et al. The autoimmune/inflammatory syndrome induced by adjuvants (ASIA)/Shoenfeld's syndrome: descriptive analysis of 300 patients from the international ASIA syndrome registry. Clin Rheumatol 2018;37:483-93.

43. FDA Executive Summary Breast Implant Special Topics. FDA. Available online: https://www.fda.gov/ media/122956/download. Published 2019. Accessed June 6, 2021.

44. Magnusson MR, Cooter RD, Rakhorst H, et al. Breast 
Implant Illness: A Way Forward. Plast Reconstr Surg 2019;143:74S-81S.

45. Tang SYQ, Israel JS, Afifi AM. Breast Implant Illness: Symptoms, Patient Concerns, and the Power of Social Media. Plast Reconstr Surg 2017;140:765e-6e.

46. Jewell ML, Jewell HL. Breast Implant-Associated Illness: Medicine by Belief, So Says Dr. Google. Aesthet Surg J 2019;39:NP87-9.

47. Dush DM. Breast implants and illness: a model of psychological factors. Ann Rheum Dis 2001;60:653-7.

48. Ahern M, Smith $M$, Chua H, et al. Breast implants and illness: a model of psychological illness. Ann Rheum Dis 2002;61:659.

49. Breiting VB, Hölmich LR, Brandt B, et al. Long-term health status of Danish women with silicone breast implants. Plast Reconstr Surg 2004;114:217-26; discussion 227-8.

50. Cohen Tervaert JW. Autoinflammatory/autoimmunity syndrome induced by adjuvants (ASIA; Shoenfeld's syndrome): A new flame. Autoimmun Rev 2018;17:1259-64.

51. Cohen Tervaert JW, Colaris MJ, van der Hulst RR. Silicone breast implants and autoimmune rheumatic diseases: myth or reality. Curr Opin Rheumatol 2017;29:348-54.

52. Shoenfeld Y, Agmon-Levin N. 'ASIA' - autoimmune/ inflammatory syndrome induced by adjuvants. $\mathrm{J}$ Autoimmun 2011;36:4-8.

53. Cohen Tervaert JW, Kappel RM. Silicone implant incompatibility syndrome (SIIS): a frequent cause of ASIA (Shoenfeld's syndrome). Immunol Res 2013;56:293-8.

54. Peters W, Smith D, Fornasier V, et al. An outcome analysis of 100 women after explantation of silicone gel breast implants. Ann Plast Surg 1997;39:9-19.

55. Mcguire PA, Haws MJ, Nahai F. Breast Implant Illness: How Can We Help? Aesthet Surg J 2019;39:1260-3.

56. BAAPS - Breast Implant Illness - what we know, and what we don't know. Available online: https://baaps.org. uk/_userfiles/pages/files/bii_information.pdf. Accessed February 17, 2020.

57. Lachmansingh DA. Breast implant illness and psychiatric implications. Ir J Psychol Med 2019. [Epub ahead of print]. doi: http://dx.doi.org/10.1017/ipm.2019.48.

58. Symptoms sometimes referred to as Breast Implant Illness - GOV.UK. Available online: https://www.gov.uk/ guidance/symptoms-sometimes-referred-to-as-breastimplant-illness. Accessed February 17, 2020.

59. Lipomodelling Guidelines for Breast Surgery. Bapras. org.uk. Available online: http://www.bapras.org.uk/docs/ default-source/commissioning-and-policy/2012-augustlipomodelling-guidelines-for-breast-surgery.pdf? sfvrsn $=0$. Published 2012. Accessed February 17, 2020.

60. Charvet HJ, Orbay H, Wong MS, et al. The Oncologic Safety of Breast Fat Grafting and Contradictions Between Basic Science and Clinical Studies: A Systematic Review of the Recent Literature. Ann Plast Surg 2015;75:471-9.

61. Delay E, Garson S, Tousson G, et al. Fat injection to the breast: technique, results, and indications based on 880 procedures over 10 years. Aesthet Surg J 2009;29:360-76.

62. Osswald R, Boss A, Lindenblatt N, et al. Does lipofilling after oncologic breast surgery increase the amount of suspicious imaging and required biopsies?-A systematic meta-analysis. Breast J 2020;26:847-59.

63. Al Sufyani MA, Al Hargan AH, Al Shammari NA, et al. Autologous Fat Transfer for Breast Augmentation: A Review. Dermatol Surg 2016;42:1235-42.

64. Coleman SR, Saboeiro AP. Fat grafting to the breast revisited: safety and efficacy. Plast Reconstr Surg 2007;119:775-85; discussion 786-7.

65. Cil TD, McCready D. Modern Approaches to the Surgical Management of Malignant Breast Disease: The Role of Breast Conservation, Complete Mastectomy, Skin- and Nipple-Sparing Mastectomy. Clin Plast Surg 2018;45:1-11.

66. Qureshi AA, Myckatyn TM, Tenenbaum MM. Mastopexy and Mastopexy-Augmentation. Aesthet Surg J 2018;38:374-84.

67. Honart JF, Reguesse AS, Struk S, et al. Indications and Controversies in Partial Mastectomy Defect Reconstruction. Clin Plast Surg 2018;45:33-45.

68. Chatterjee A, Gass J, Patel K, et al. A Consensus Definition and Classification System of Oncoplastic Surgery Developed by the American Society of Breast Surgeons. Ann Surg Oncol 2019;26:3436-44.

69. Schwartz JD. New Approach to Oncoplastic Breast Conservation: Combining Autologous Volume Replacement and the Wise-pattern Mammaplasty. Plast Reconstr Surg Glob Open 2018;6:e1987.

70. Hall-Findlay EJ. The three breast dimensions: analysis and effecting change. Plast Reconstr Surg 2010;125:1632-42.

71. Regnault P. Breast ptosis. Definition and treatment. Clin Plast Surg 1976;3:193-203.

72. Hidalgo DA, Spector JA. Mastopexy. Plast Reconstr Surg 2013;132:642e-56e.

73. Hall-Findlay E, Evans G. Aesthetic And Reconstructive Surgery Of The Breast. 1st ed. Philadelphia, PA: Saunders Elsevier, 2010. 
74. Spear SL, Kassan M, Little JW. Guidelines in concentric mastopexy. Plast Reconstr Surg 1990;85:961-6.

75. Hall-Findlay EJ. Vertical breast reduction with a mediallybased pedicle. Aesthet Surg J 2002;22:185-94.

76. Rohrich RJ, Gosman AA, Brown SA, et al. Mastopexy preferences: a survey of board-certified plastic surgeons. Plast Reconstr Surg 2006;118:1631-8.

77. Wise RJ. A preliminary report on a method of planning the mammaplasty. Plast Reconstr Surg (1946) 1956;17:367-75.

78. Lejour M. Vertical mammaplasty and liposuction of the breast. Plast Reconstr Surg 1994;94:100-14.

79. Davison SP, Mesbahi AN, Ducic I, et al. The versatility of the superomedial pedicle with various skin reduction patterns. Plast Reconstr Surg 2007;120:1466-76.

80. Hammond DC, Alfonso D, Khuthaila DK. Mastopexy using the short scar periareolar inferior pedicle reduction technique. Plast Reconstr Surg 2008;121:1533-9.

81. Wong C, Vucovich M, Rohrich R. Mastopexy and

Cite this article as: Roy PG, Yan Z, Nigam S, Maheshwari K. Aesthetic breast surgery: putting in context-a narrative review. Gland Surg 2021;10(9):2832-2846. doi: 10.21037/gs-20-892 reduction mammoplasty pedicles and skin resection patterns. Plast Reconstr Surg Glob Open 2014;2:e202.

82. di Summa PG, Oranges CM, Watfa W, et al. Systematic review of outcomes and complications in nonimplantbased mastopexy surgery. J Plast Reconstr Aesthet Surg 2019;72:243-72.

83. Gupta V, Yeslev M, Winocour J, et al. Aesthetic Breast Surgery and Concomitant Procedures: Incidence and Risk Factors for Major Complications in 73,608 Cases. Aesthet Surg J 2017;37:515-27.

84. Blomqvist L, Eriksson A, Brandberg Y. Reduction mammaplasty provides long-term improvement in health status and quality of life. Plast Reconstr Surg 2000;106:991-7.

85. Thorek M. Possibilities in the reconstruction of the human form 1922. Aesthetic Plast Surg 1989;13:55-8.

86. Benelli L. A new periareolar mammaplasty: the "round block" technique. Aesthetic Plast Surg 1990;14:93-100. 